\title{
The effects of urban development and current green infrastructure policy on future climate change resilience
}

\author{
$\underline{\text { Charlotte Shade }}^{1}, \underline{\text { Peleg Kremer }}^{1}, \underline{\text { Julia S. Rockwell }}^{2}$ and Keith G. Henderson $^{1}$
}

\begin{abstract}
Governments around the world are beginning to plan for the effects of climate change. In Philadelphia, Pennsylvania, USA, the city is implementing a variety of green infrastructure practices through the program Green Cities, Clean Waters to meet state and federal stormwater regulations. Though not a current goal of the program, when implemented effectively, a cobenefit of green infrastructure is increased local resilience to potential ecosystem alterations, such as increasing summer temperatures and heavier precipitation, also defined as climate change adaptation. We analyzed the potential of the Green City, Clean Waters plan to increase the city's resilience to the future consequences of climate change. Three future landcover models of Philadelphia were used to analyze climate change adaptation through green infrastructure in the near term, midcentury, and end of century under two climate change scenarios. Green infrastructure was overall found to locally decrease runoff throughout Philadelphia over time. Green infrastructure impact on surface temperature showed mixed results. Impact on runoff and surface temperature differed between types of green infrastructure. As the city is forecasted to grow warmer, wetter, and more urbanized over the century, runoff and local temperatures will increase on average throughout the city, despite the planned growth in green infrastructure. If increased resilience is to keep pace with climate change, the city government will need to expand its green infrastructure plan and consider the cobenefit of climate change adaptation when planning new projects. Additionally, for true climate change resiliency to be achieved, green infrastructure implementation must be connected to citywide greening efforts, accelerate and continue beyond the near term for localities to function as they do today.
\end{abstract}

Key Words: climate change resilience; cobenefits; green stormwater infrastructure; urban stormwater runoff; urban surface temperature

\section{INTRODUCTION}

Cities are defined by their dense, built (grey) infrastructure, which support everyday functions such as transportation, safety, water utilities, energy utilities, sanitation, and communication (Andersson et al. 2019). The decisions we make about urban ecosystems today are important for the future resilience of urban environments. As cities continue to face rapid changes from technological advances, population growth, and climate change, the distribution and effectiveness of ecosystem services (ES) will become more important. The loss of local climate and stormwater regulating services poses a particular threat to the functionality of urban ecosystems and the safeguarding of vulnerable residents (Sussams et al. 2015). In many areas worldwide, the consequences of urbanization and climate change will continually amplify each other over time, creating difficult living conditions for city residents. Ecosystem functions that manage stormwater and maintain local climate or temperature regulation can support the resilience of cities as they respond to the consequences of climate change.

Many cities are currently adopting policies to integrate green infrastructure (GI) with traditional grey infrastructure to address urban resiliency, water quality, and sustainability goals (Grimm et al. 2015, Kabisch et al. 2017, Meerow and Newell 2017). Specific to the consequences of climate change, past studies have found evidence that GI can reduce such effects by providing additional climate regulating ES. For example, plants can decrease local temperatures through evapotranspiration and increase infiltration of runoff into the ground, increasing resiliency for cities (Gill et al. 2007, Brown et al. 2012, Demuzere et al. 2014, Jones and Somper 2014, Hrdalo et al. 2015, Sussams et al. 2015, Meerow and Newell 2017). Specifically, Gill et al. (2007) found that after adding $10 \%$ green cover in high-density residential areas in Greater
Manchester, UK, maximum surface temperatures decreased by $2.4^{\circ} \mathrm{C}$ to $2.5^{\circ} \mathrm{C}$ under the 2080s Low and High greenhouse gas emissions scenarios, respectively, compared to the 1961-1990 baseline. Furthermore, Liu et al. (2015) note that GI used for stormwater management can reduce the negative impacts from the intensification and frequency of rain events on hydrology and water quality by reducing runoff and controlling the movement of pollutants. It is important to assess the need for ES and the ability of GI to provide those ES so cities can take action now to mitigate the consequences of future climate change.

Although one evaluation framework is not expected to be beneficial across all situations, this work incorporates two interconnected systemic factors, which have been identified as important for evaluating the flow (or hindrance) of ES: the layout and intersection of GI and grey infrastructure; and the institutional arrangement and implementation approaches around green-blue infrastructure (GBI), i.e., factors such as ownership and user rights, policy intentions, and prescriptions (Andersson et al. 2019). Assessing the function of GI in this context requires quantifying and evaluating its potential to provide ES and to assess this information relative to vulnerable areas most in need of the potential ES benefits. Similar to physical infrastructure, institutions and policies need to be assessed for their targets, strategies, monitoring, and evaluation practices (Borgström et al. 2006, Stead and Meijers 2009, Cejudo and Michel 2017), which may reduce or enhance the contribution of GI to climate resilience and human well-being (Andersson et al. 2019). Various forms of GI and their resulting ES are inherently different in how they relate to the factors (Andersson et al. 2019); promoting and managing this multifunctionality needs to be understood further.

${ }^{1}$ Department of Geography \& the Environment, Villanova University, Villanova, Pennsylvania, USA, ${ }^{2}$ Climate Change Adaptation Program, Office of Watersheds, Philadelphia Water Department, Philadelphia, Pennsylvania, USA 
In this work, we incorporate two systemic factors, physical infrastructure and institutions, to the GI program Green City, Clean Waters (GCCW) in Philadelphia, Pennsylvania, USA as a case study to understand whether GI planning that is driven by current water quality regulations can also amplify ES benefits that increase climate change resilience. Three future landcover models of Philadelphia (Shade and Kremer 2019) are used to understand how the spatial configuration of different types of GI, the urban ecosystem functions that flow from it, and the institutional policies that govern GI planning and design may enhance or hinder the ability to increase resilience to future climate change. The landcover models predicted continued urbanization across the city. Hypothetical spatial distribution of GI was based on assumption of full implementation of the 25year GCCW by 2036 (Shade and Kremer 2019). Specifically, we examine the effects of climate change in the near term (2020 to 2046), midcentury (2047 to 2073), and the end of the century (2074 to 2099) under moderate and extreme climate change scenarios.

\section{METHODS AND MATERIALS}

\section{Institutional framework: Green City, Clean Waters}

In 2011 the Philadelphia Water Department (PWD) launched Green City, Clean Waters (GCCW) to reduce combined sewer overflow events and improve water quality in the City's creeks and rivers. The policies of GCCW are driven by the need to meet Pennsylvania Department of Environmental Protection (PADEP) and federal Clean Water Act regulations (Philadelphia Water Department 2011). GCCW primarily uses green stormwater infrastructure as a way to alleviate the amount of runoff that flows into storm drains and, eventually, into the Schuylkill and Delaware rivers and their tributaries. PWD measures the program's success using the concept of "greened acres" (GAs), defined as enough GI to manage one inch of stormwater from one acre of drainage area; approximately 103 $\mathrm{m}^{3}$ (27,158 gallons; Philadelphia Water Department 2016).

This program is the first in the United States that prioritizes GI over traditional grey infrastructure to manage stormwater runoff. Although some GI was built prior to 2011, construction of GCCW projects officially began in 2011 and will continue through 2036. GI projects are funded through credits to private developers, grants, and public works projects. In an effort to create more GAs, GCCW puts forth eight different best management practices to reduce the amount of impermeable surfaces within the city: (1) green streets, (2) green schools, (3) green public facilities, (4) green parking, (5) green open space, (6) green industry, business, commerce, and institutions, (7) green alleys, driveways, and walkways, and (8) green homes (Philadelphia Water Department 2011). PWD implements a variety of vegetative GI practices throughout the city, such as rain gardens, man-made wetlands, tree trenches, planters, swales, and green roofs, as well as nonvegetative practices like cisterns, trenches, bump outs, basins, and pervious pavement (Philadelphia Water Department 2011). By the year 2036, GCCW will have implemented at least $36 \mathrm{~m}^{3}$ (9564 GAs) and reduced the amount of pollutants entering local streams and rivers by capturing $85 \%$ of combined sewer overflow volume (Philadelphia Water Department 2011).

\section{Predicting future landcover in Philadelphia}

The three future landcover models were created using a combination of cellular automata, machine learning, and Markov chain analysis to predict high resolution land use/landcover changes in Philadelphia (Shade and Kremer 2019). The methods presented in Shade and Kremer (2019) to create a landcover model of the year 2036 (near term) were replicated to create landcover models of the years 2060 and 2087, representing the midcentury and end of century, respectively. The landcover models assumed full implementation of Philadelphia's green infrastructure program by 2036, resulting in over 3845 greened hectares $(9500$ acres), and incorporated past temporal trends of urbanization. Urbanization trends were driven by elevation, slope, distance to existing roads and rivers, and the likelihood of categorical changes. The growth in GI was driven by GCCW policies.

\section{Modeling the future climate in Philadelphia}

To understand the effects of future climate change in Philadelphia, downscaled global climate model output and processing tools were acquired from the Intergovernmental Panel on Climate Change (IPCC) and the U.S. Department of Transportation (US DOT), respectively (Maurer et al. 2007). Downscaled Bias-Correction Constructed Analogues version 2 (BCCAv2) Coupled Model Intercomparison Project Phase 5 (CMIP5) climate projection output (Bureau of Reclamation 2014) were acquired for Philadelphia using the following coordinates: $40.0625 \mathrm{~N},-75.1875 \mathrm{E} ; 40.0625 \mathrm{~N},-75.0625 \mathrm{E}$; $39.9375 \mathrm{~N},-75.3125 \mathrm{E}$; and $39.9375 \mathrm{~N},-75.1875 \mathrm{E}$. Gridded output for 19 different global climate models (GCMs) were downloaded for Representative Concentration Pathways (RCP) 4.5 and 8.5 (Moss et al. 2008). In RCP4.5, greenhouse gas concentration trajectories peak around 2040 and then decline, while in RCP8.5, greenhouse gas concentrations are projected to rise throughout the 21st century (Meinshausen et al. 2011).

The USDOT CMIP Climate Data Processing Tool (ICF International 2016) was used to process statistically downscaled output from 19 GCMs to predict future air temperature and precipitation within a specified time period. The tool was used to calculate the air temperature of "very hot summer days," or air temperature of the 95th percentile in June, July, and August, for the near term (2020-2046), midcentury (2047-2073), and the end of century (2074-2099) for RCP4.5 and RCP8.5 (Table 1). Very hot day thresholds for the present-day period (1992-2018) were reported to be $33.5^{\circ} \mathrm{C}$.

Table 1. Projected 95th percentile daily summer air temperature $\left({ }^{\circ} \mathrm{C}\right)$ calculated with the U.S. Department of Transportation Coupled Model Intercomparison Project Climate Data Processing Tool.

\begin{tabular}{lll}
\hline \hline & RCP4.5 & RCP8.5 \\
\hline Near term (2020-2046) & $34.2^{\circ} \mathrm{C}$ & $34.4^{\circ} \mathrm{C}$ \\
Midcentury (2047-2073) & $35.1^{\circ} \mathrm{C}$ & $36.2^{\circ} \mathrm{C}$ \\
End of century (2074-2099) & $35.5^{\circ} \mathrm{C}$ & $37.9^{\circ} \mathrm{C}$ \\
\hline
\end{tabular}

The downscaled output from the 19 GCMs were used to calculate precipitation delta change factors (DCFs) for each of the future time periods (Maimone et al. 2019). Each of the 19 GCMs provides daily precipitation output for each climate change 
scenario up to the year 2099. Because summer is the season with the heaviest rain events in Philadelphia, dry days $(0 \mathrm{~mm}$ of precipitation) were removed from the daily precipitation output and then wet days of the summer months (June, July, and August) were ranked by percentile for the near term, midcentury, and end of century. For the 95th percentile precipitation value, the value was adjusted by averaging it with the five percentile values immediately above and below it. This method not only smooths the distribution of percentiles, but also minimizes the undue influence of any anomalies. The present-day 95th percentile wet day was calculated using GCM data from 1992 to 2018. After the 95th percentile wet day was calculated for each model for each time period, the present-day modeled value was subtracted from each future modeled value, respective of each GCM and RCP, to determine the DCF. The DCFs for each time period were averaged together across the 19 GCMs, resulting in final DCFs (Table 2). The final DCFs were added to the observed present-day 95th percentile wet day of $41.125 \mathrm{~mm}$, which was calculated using daily precipitation data recorded at the Philadelphia International Airport. These data were retrieved from the Global Historical Climatology Network of NOAA's National Climatic Data Center for the years 1992-2018 (Menne et al. 2012).

Table 2. Delta change factors (DCF) and the projected 95th percentile daily total rainfall $(\mathrm{mm})$ based on the 19 GCMs for each time period, respective of climate change scenario.

\begin{tabular}{lccccc}
\hline \hline & \multicolumn{2}{c}{ RCP4.5 } & & \multicolumn{2}{c}{ RCP8.5 } \\
\cline { 2 - 3 } Time Periods & DCF & Rainfall & & DCF & Rainfall \\
\hline Near term (2020-2046) & 0.38 & 41.50 & & 0.48 & 41.61 \\
Midcentury (2046-2073) & 1.07 & 42.19 & & 1.02 & 42.15 \\
End of century (2074-2099) & 0.88 & 42.01 & & 1.51 & 42.64 \\
\hline
\end{tabular}

\section{Runoff analysis}

The generation of urban runoff was modeled using the Soil Conservation Service Curve Number (CN) method (USDA 1986). This model estimates rainfall runoff based on ground coverage, soil type, and amount of precipitation. For the purpose of this analysis, antecedent moisture conditions were assumed to be dry, so landcover absorption was expected to function at maximum capacity (Maragno et al. 2018). Final runoff in $\mathrm{mm}$ is calculated with the following equations (Equations 1-3):

$$
\begin{gathered}
Q= \begin{cases}\left(P-I_{a}\right)^{2} /\left(P-I_{a}+S\right), & P \geq I_{a} \\
0, & P \leq I_{a}\end{cases} \\
I_{a}=\lambda \cdot S \\
S=\frac{25400}{C N}-254
\end{gathered}
$$

Where $\mathrm{Q}$ is the rainfall runoff depth $(\mathrm{mm}), \mathrm{P}$ is the precipitation depth ( $\mathrm{mm}$ ) calculated from the DCFs (Table 1), S is the potential maximum water storage in soil ( $\mathrm{mm}), \mathrm{CN}$ is the tabulated value of Curve Number (dimensionless) ranging from 0 to 100 (Table $3), I_{a}$ is the initial abstraction of rainfall $(\mathrm{mm})$, and $\lambda$ is the initial abstraction coefficient (constant) of 0.05 used for urban settings (Lim et al. 2006, Ling and Yusop 2014).
The $\mathrm{CN}$ values were derived from the U.S. Department of Agriculture's (USDA) TR-55 (USDA 1986) and a literature review of other $\mathrm{CN}$ research (Table 3; The Center for Neighborhood Technology 2007, Water Environment Research Foundation 2009, Maragno et al. 2018, Philadelphia Water Department 2018a, Valparaiso Engineering Department [date unknown]). For landcover located in an area that is a combination of hydrologic soil groups (i.e., $\mathrm{A} / \mathrm{D}, \mathrm{B} / \mathrm{D}$, and $\mathrm{C} / \mathrm{D}$ ), the $\mathrm{CN}$ value of the two hydrologic soil groups were averaged together, respective of landcover, because we could not know where the water table sat beneath the land. There was not enough information available to assess the condition of the grass areas, and so the $\mathrm{CN}$ values of each condition were averaged together. If the hydrologic soil group was only classified as urban, then the average $\mathrm{CN}$ of all the soil groups for the respective land covers was used in the calculations.

Assumptions were made as to which types of GI may be implemented under specific landcover transitions, because specific types of GI were not predicted by the landcover models (Shade and Kremer 2019). For example, when buildings transitioned to GI, green roofs were assumed because it can be expected that the city would not tear down a building to develop GI, but a green roof may be implemented on the building. Trees transitioning to GI were assumed to be tree trenches because it is not likely that the city would remove a tree for GI implementation. Roads/railroads transitioning to GI were assumed to be permeable pavement because roads/railroads would not be removed for GI. Water and paved surfaces transitioning to GI were assigned a weighted average $\mathrm{CN}$ of all types of GI except for green roofs, because many types of GI could be implemented in these locations (although water transitioning to GI is most likely an error in the future landcover model). Similarly, grass and soil transitioning to GI were assigned a weighted average $\mathrm{CN}$ of all types of GI except for green roofs and pervious pavement. Weights for the average CNs were based on the current number of GI projects for each type of GI and it was assumed that the proportion of each type of GI project would stay the same in the future. The number and types of GI projects were found using green infrastructure GIS data from the Philadelphia Water Department (Philadelphia Water Department 2018b).

To analyze changes in future ecosystem function, the future landcovers of Philadelphia in 2036, 2060, and 2087 (Shade and Kremer 2019) were used to asses runoff conditions in the near term, midcentury, and end of century. The landcover of Philadelphia in 2015 was used as a baseline to represent present day conditions. Within each landcover, each pixel was assigned a $\mathrm{CN}$ depending on its type of land use and location within a hydrologic soil group. Hydrologic soil group spatial data were acquired from the Philadelphia Water Department (Philadelphia Water Department [date unknown]). After every pixel was assigned a $\mathrm{CN}$, the estimated amount of runoff during a 95th percentile rain event was calculated using Equations 1-3 in the raster calculator tool in ESRI ArcGIS 10.6 (ESRI 2018).

\section{Surface temperature analysis}

Surface temperature is used here as proxy for a set of climate regulating ecosystem functions (Schwarz et al. 2011, Hamstead et al. 2016). To predict the spatially explicit distribution of surface temperature throughout the city, a combination of Landsat 
Table 3. Curve numbers of different land covers and types of green infrastructure.

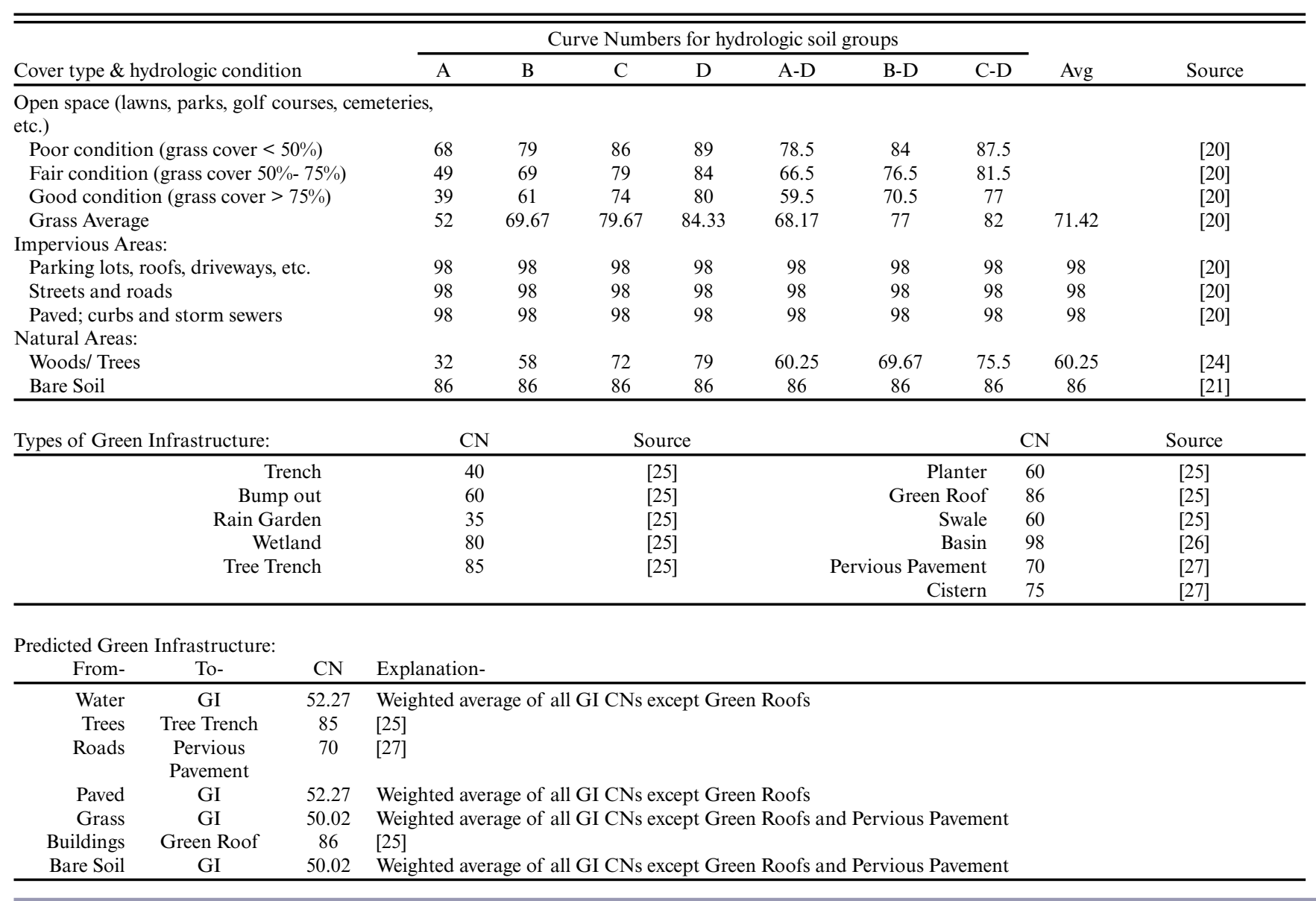

surface temperature and air temperature data from the Northeast Philadelphia Airport for two summer days were used to estimate the impact of an increase in air temperature on surface temperature. Provisional surface temperature Landsat Analysis Ready Data ${ }^{[1]}$ of Philadelphia were acquired from the U.S. Geological Survey (Cook 2014, Cook et al. 2014, USGS 2018), and any clouds and cloud shadows were removed from the images. Satellite images were chosen based on the date of the image (warmer months; May through September), quality of the image (minimum cloud coverage), air temperature when the image was taken, and the temporal proximity of the satellite image to available landcover models (2008, 2010, and 2015). Based on these criteria, two land surface temperature images from the summer of 2010 and 2011 were chosen for the analysis.

The hourly dry bulb air temperature, recorded at the Northeast Philadelphia Airport, was acquired from NOAA's Local Climatological Data (NOAA 2019). Each image was matched with its air temperature at the approximate time when the image was taken (Table 4). Air temperature recorded at the Northeast Philadelphia Airport was used as representative of the air temperature in the city at the time, although we recognize air temperature likely varied throughout the city at the given times.
Future surface temperatures were calculated using a ratio between the change in air temperature and change in surface temperature (Equations 4-5):

$$
\begin{gathered}
S T_{\text {Future }}=\left(x *\left(A T_{\text {Future }}-A T_{28 . A u g .10}\right)\right)+S T_{28 . A u g .10} \\
\frac{\left(S T_{30 . J u l .11}-S T_{28 . A u g .10}\right)}{x}=\frac{\left(A T_{30 . J u l .11}-A T_{28 . A u g .10}\right)}{\Delta 1 \text { degree AT }}
\end{gathered}
$$

Where ST represents the surface temperature of the city in the Landsat surface temperature data; AT represents the air temperatures for present day, acquired from NOAA (NOAA 2019), and the forecasted future temperatures (Table 1). The subscripts of 30.Jul.11 and 28. Aug. 10 are the dates of the present day surface temperatures and air temperatures (Table 4). The subscript Future represents the near-term, midcentury, and endof-century time periods being analyzed. Finally, $x$ represents the change in surface temperature for every one-degree change in air temperature. The conversion factor $x$ varies from pixel to pixel. For landcover pixels that were predicted to change in the future, surface temperature was calculated as a local average of pixels with the same landcover class. 
Table 4. The date of the Landsat images, their scene center time (EST), the corresponding dry bulb temperature (oC), and time of the temperature measurement (EST).

\begin{tabular}{lccc}
\hline \hline $\begin{array}{l}\text { Date of Landsat } \\
\text { Image }\end{array}$ & $\begin{array}{c}\text { Scene Center } \\
\text { Time (EST) }\end{array}$ & $\begin{array}{c}\text { Dry Bulb } \\
\text { Temp }\left({ }^{\circ} \mathrm{C}\right)\end{array}$ & $\begin{array}{c}\text { Time of Temp } \\
\text { (EST) }\end{array}$ \\
\hline 30-Jul-11 & $10: 28: 51 \mathrm{AM}$ & 30.6 & $10: 54 \mathrm{AM}$ \\
28-Aug-10 & $10: 30: 09 \mathrm{AM}$ & 26.1 & $10: 54 \mathrm{AM}$ \\
\hline
\end{tabular}

\section{Overlap and trade-offs in runoff and surface temperature}

The spatial distribution of stormwater runoff and local surface temperatures were analyzed to evaluate their current and future spatial overlap, providing an indication of whether current GCCW policies enhance the ability to increase climate change resilience cobenefits. The spatial data for all runoff (Q) and surface temperature (ST) projections were reclassified to a binary system to indicate areas above the average (high) or below the average (low), respective of each time period and climate change scenario. The reclassified data of runoff and surface temperature were then combined in a quadrant analysis, again respective of each time period and climate change scenario, to identify potential areas of high runoff and high surface temperature (high-high); high runoff and low surface temperature (high-low); low runoff and high surface temperature (low-high); and low runoff and low surface temperature (low-low).

Finally, the impact of the type of GI was analyzed. GI types were broken into three categories: vegetative (GI with vegetation), nonvegetative (GI without any vegetation, such as storage basins or pervious pavement), and unknown (future GI that could be either subtype), to understand how future cobenefits may align with different GI practices.

\section{RESULTS}

\section{Stormwater runoff}

The change in future runoff was calculated for each climate change scenario throughout Philadelphia (Fig. 1). Results suggest that by the end of the century under RCP 8.5, runoff could increase over $25 \mathrm{~mm}$ in some areas during a large rain event (Fig. 1). Contrastingly, runoff could also decrease in some areas by over $20 \mathrm{~mm}$ per large rain event (Fig. 1). Increases in runoff can be mostly attributed to new urban areas such as buildings, roads/ railroads, and other paved surfaces (Fig. 2). Over time, through each climate change scenario, impervious surfaces lead to an average increase in runoff of about 4.5 to $6.5 \mathrm{~mm}$ (Fig. 2). Contrastingly, green spaces such as trees, grass/shrubs, and soil result in smaller increases of runoff, usually less than $1 \mathrm{~mm}$ (Fig. 2). On average throughout the city, GI results in a future decrease in runoff (Fig. 2).

\section{Surface temperature}

The temperature of some surfaces in Philadelphia on very hot days could rise by more than $20^{\circ} \mathrm{C}$ compared to present day, which becomes more common by the end of the century (Fig. 3). Increases in surface temperature $\geq 10^{\circ} \mathrm{C}$ compared to present day are predicted to become very frequent throughout the city over time, especially under RCP8.5 (Fig. 3). The increase in surface temperatures are consistent with the projected urbanization of Philadelphia (Shade and Kremer 2019) and predicted increases in very hot summer temperatures due to climate change (Table 1). Additionally, in a few areas of the city, surface temperature could decrease by more than $10{ }^{\circ} \mathrm{C}$ compared to present-day surface temperatures; however, decreases in surface temperature are predicted to become very rare over time (Fig. 3). Water, followed by trees and grass, is predicted to remain the coolest landcover type in the city, experiencing the lowest increase in average temperature throughout the future time periods. Roads, buildings, other paved surfaces, and overall, the GI category, are among the categories showing the highest increase in average temperature and temperature change (Fig. 4).

Fig. 1. Predicted changes in the future amount of runoff ( $\mathrm{mm}$ ) from each climate change scenario during a 95 th percentile rain event.

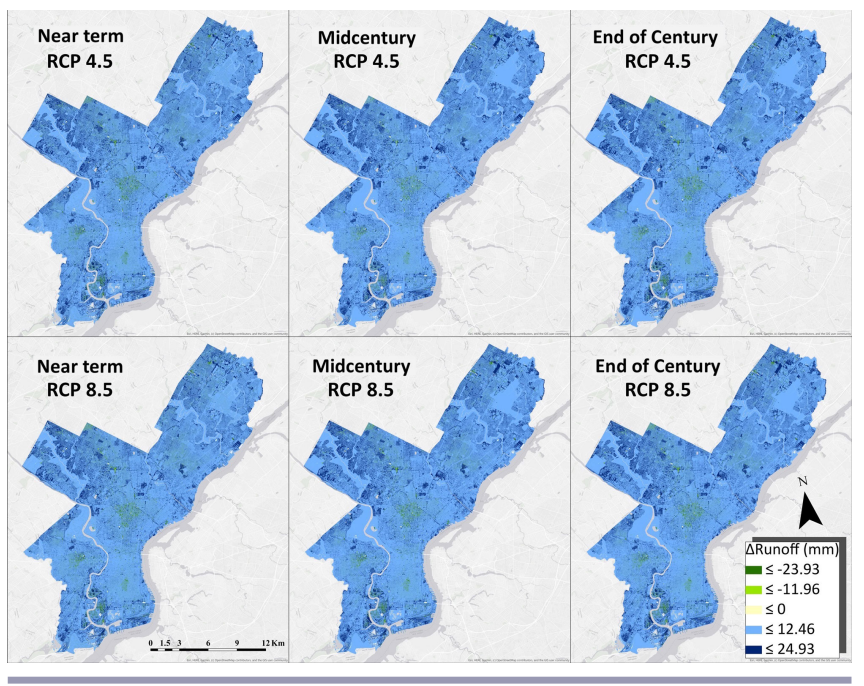

Fig. 2. The average change in per-pixel runoff associated with each type of landcover, respective of time period and climate change scenario.

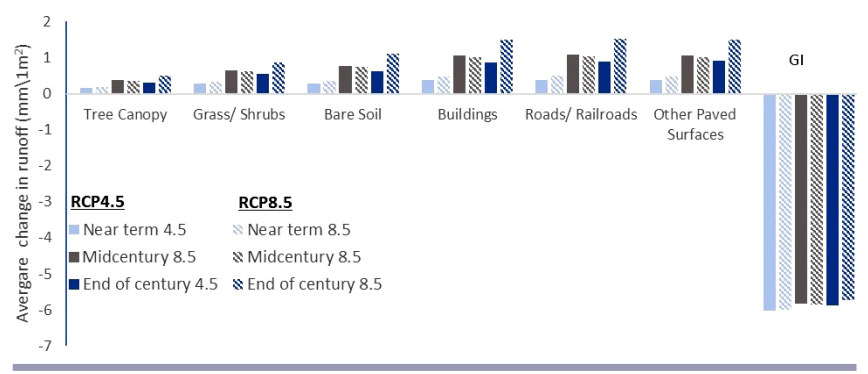

Overlap and trade-offs in runoff and surface temperature Within the densely built urban environment, runoff and surface temperature were high (above average) throughout most of the city (Fig. 5). The dominance of the spatial distribution of the high-high combination is predicted to stay consistent throughout the end of the century, as the city continues to urbanize, and summers continue to warm. Locations exhibiting low runoff and 
low ST exist mostly around waterways and in forested areas demonstrating the importance and contribution of green spaces that are not engineered GIs (Fig. 5). However, low-low relationships are predicted to spatially decrease throughout the city over time, being replaced with landcover that exhibits high runoff and low surface temperature, indicative of low intensity urban development. Areas of low runoff and high surface temperature are rare throughout the city and are mostly associated with GIs.

Fig. 3. Predicted change in surface temperatures over time, under climate change scenarios RCP4.5 and RCP8.5 on a 95th percentile hot day.

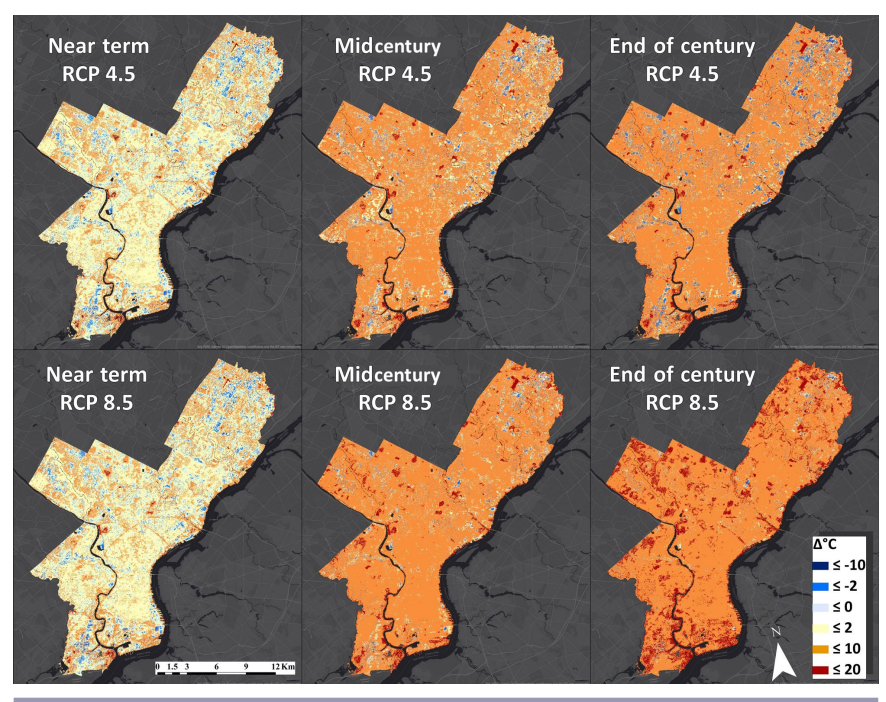

Fig. 4. (A) Average surface temperature by time period. (B)

Average change in surface temperature by landcover, time period, and climate change scenario.
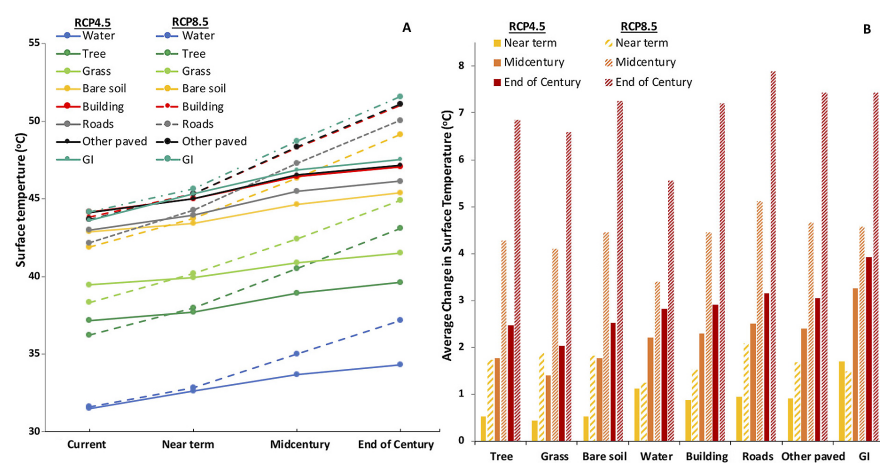

The reductions in runoff and surface temperature associated with vegetative, nonvegetative, and unknown subtypes of GI are predicted to operate similarly in the near term (Fig. 6). Throughout each future time period, a large proportion of each subtype of GI demonstrates a mismatch where runoff is low while surface temperatures are high. This means that while the GCCW program is clearly producing reduction in runoff as intended, spontaneous climate regulating cobenefits are limited. By the mid to end of century, vegetative GI is predicted to see a higher increase in lowlow synergy compared to nonvegetative GI. Similarly, in the midto end-of-century time frame, vegetative GI is predicted to see more of a decrease in high-high match-up compared to nonvegetative GI. Additionally, nonvegetative GI is predicted to exhibit a greater mismatch between runoff and surface temperature throughout the end of the century, specifically low runoff and high surface temperature, compared to vegetative GI (Fig. 6).

Fig. 5. Comparison of predicted runoff $(\mathrm{Q})$ and surface temperature (ST) regulating services over time under RCP4.5 and 8.5. High $(\mathrm{H})$ measurements are above average and low (L) measurements are below average.

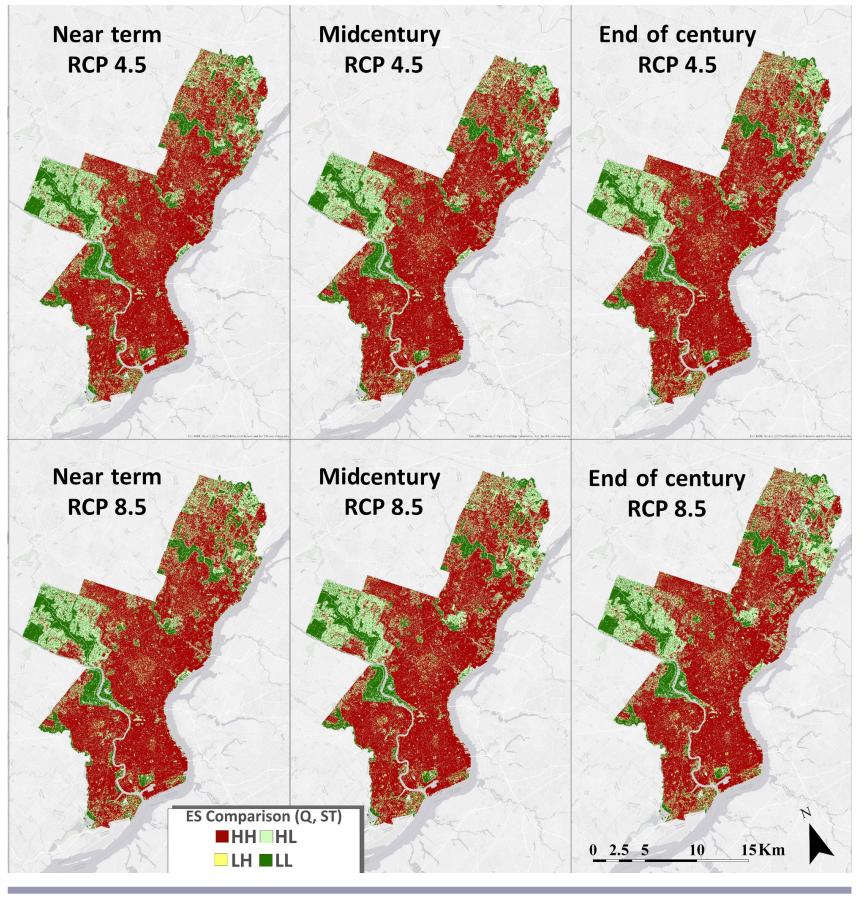

Fig. 6. Comparison of predicted runoff (Q) and surface temperature $(\mathrm{ST})$ regulating services at GI locations. High $(\mathrm{H})$ measurements are above average and low (L) measurements are below average, respective of time period and climate change scenario.

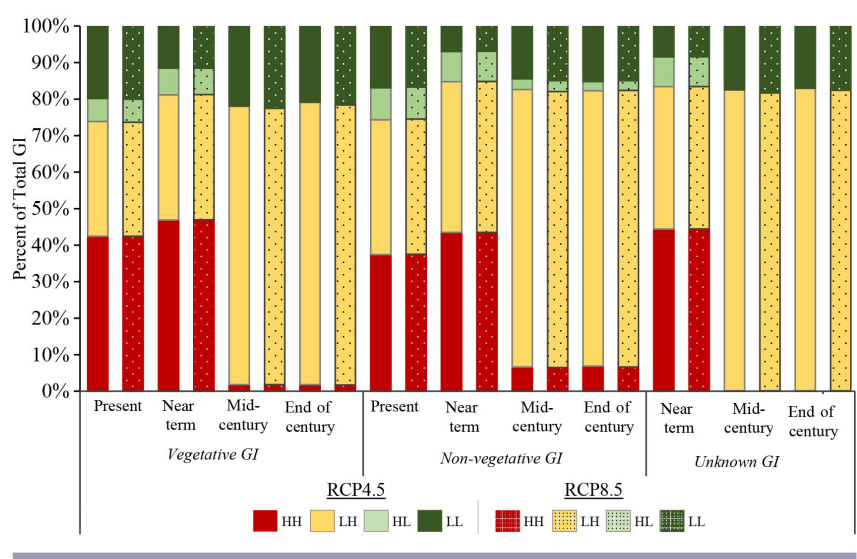

\section{DISCUSSION}

We find that overall, climate change will present resilience challenges to Philadelphia with both runoff and surface 
temperatures predicted to increase across most of the city's landscape. We find that current GI implementation indeed contributes to runoff reductions where implemented. However, these systems provide limited contribution to surface temperature control, most likely because of the limited proportion of vegetative GI. Because current GCCW policies are strictly driven by the goal of decreasing runoff, current GI implementation practices present limited opportunities to amplify the cobenefit of surface temperature regulation and promote multifunctional resilience outcomes. However, it is important to note that the feasibility of maximizing climate resilience cobenefits needs to be considered in terms of both physical infrastructure and the institutional framework. Physical infrastructure considerations must include the design context for GI systems. The age and density of Philadelphia can constrain the type, size, and feasibility of implementing certain GI projects. Additionally, our analyses predict that GI implementation will need to continue beyond the end date of GCCW in 2036 as climate change continues to increase precipitation and surface temperature through the rest of the century. In regard to the institutional framework, maximizing climate resilience cobenefits will require broader acceptance and prioritization of approaches to green the city, including changing or adopting new city standards and policies. This process would go beyond the jurisdiction of any single city agency and any one driver, policy, or regulation.

GCCW does enhance the city's overall resilience against increases in runoff; however, because of the projected impact of climate change, the program in its current state will not completely prevent future increases in runoff compared to present day. Downscaled global climate models predict that 95 th percentile summer rain events will continue to increase in intensity throughout this century in Philadelphia (Maurer et al. 2007). Our analysis suggests that GI could decrease runoff by over $30 \mathrm{~mm}$ during future large rain events when it replaces impervious landcovers (Fig. 1). For example, when impervious rooftops and roads are replaced with their respective GI counterparts, green roofs and permeable pavement, precipitation can readily infiltrate into the ground instead of flowing over the city's surfaces and polluting waterways. Specifically, we found that the largest decreases in runoff are due to the transformation of other paved surfaces (such as parking lots and alleys) to GI. This finding is plausible. The Philadelphia Water Department has two management strategies that address paved surfaces directly: green parking, and green alleys, driveways, and walkways (Philadelphia Water Department 2011). Parking lots, alleys, and driveways can all be replaced with pervious pavement. Walkways or sidewalks can also be replaced with pervious pavement and parts of the sidewalks may be replaced with vegetation, such as street trees or bump outs. These types of transformations toward GI will aid in runoff mitigation. However, our analysis establishes that it may have limited impact on surface temperature control as GCCW does not explicitly consider future surface temperature increases.

The change in future runoff due to climate change and landcover change varies spatially across the city. The landcover models used in this study predict that some areas in the city are expected to become still more densely urbanized (Shade and Kremer 2019), resulting in intensified runoff and local flooding. Implementation of GI strategies in these areas is critical to enhance the city's resilience to climate change. Further investigation is needed to understand actual water flow and local flooding patterns throughout the city. Additionally, demographics and socioeconomic data by neighborhood should also be analyzed to understand potential at-risk populations, and social and cultural factors that could inform potential GI solutions (Andersson et al. 2019). City policies and regulations including zoning codes, urban sustainability goals, future development/land use, etc., need to be connected and inform one another for a more holistic, citywide approach.

The results of this runoff analysis are comparable to those found in a study in the Greater Manchester area in the UK, where the total runoff from a further urbanized city was found to be 16.0 million $\mathrm{m}^{3}$ for a $28 \mathrm{~mm}$ rainfall event in the 2080s (Gill et al. 2007). Increased runoff and consequent local flooding can result in both physical and mental illnesses, and damage vulnerable nearby buildings (Gill et al. 2007). In Philadelphia, the authors of Growing Stronger: Toward a Climate-Ready Philadelphia (Office of Sustainability and ICF International 2015), report that increased stormwater runoff could affect source water quality in the Greater Philadelphia region, potentially affecting the drinking water treatment process at PWD. It is important to note that Philadelphia's current GI program is not intended to mitigate extreme flooding scenarios that result from large storms, but our findings support that it can help incrementally alleviate increases in runoff that have resulted from continued urbanization.

According to the IPCC, summer air temperatures on 95th percentile hot days are also predicted to keep rising in Philadelphia (Maurer et al. 2007), which will be amplified by the dark impervious surfaces throughout the city. Surface temperature has often been used as proxy for ambient air temperature mainly for reasons of data availability (Schwarz et al. 2011, Hamstead et al. 2016, Kremer et al. 2018), because impervious surfaces can heat up significantly more than the air temperature, increasing the local temperature in a city. We found that surface temperatures of some areas in Philadelphia could increase by over $20^{\circ} \mathrm{C}$ by the end of the century under RCP8.5 as urbanization escalates (Fig. 3). As GCCW continues to implement GI practices across Philadelphia, it is important to consider surface temperature throughout the city so that GI practices that provide multiple ES are prioritized wherever possible for installation, maximizing potential for overall climate change resilience. Recognizing that increased resilience is a citywide objective, other Philadelphia government agencies and organizations, in addition to PWD, should explore opportunities to implement GI in a way that enhances multifunctional climate resilience.

The biophysical features of greenspace in urban areas, through the provision of cooler microclimates, offer the potential to help urban areas adapt to the extreme summer temperatures resulting from climate change (Gill et al. 2007). In Berlin, surface temperatures were found to be lower in areas consisting of a combination of trees, grass, and soil, and warmer for composite classes that include components of the built environment (Kremer et al. 2018). Additionally, adding 10\% more green space in town centers was found to keep maximum surface temperatures at or below the current baseline levels up to the 2080s considering climate change (Gill et al. 2007).

In Philadelphia, the surface temperature for the most urbanized areas of the city has been found to be $2.2^{\circ} \mathrm{C}$ to $4.5^{\circ} \mathrm{C}$ higher than the nearby rural average temperature (Office of Sustainability and 
ICF International 2015). Adults over 65 years old, young children, and those in poverty without air conditioning are at risk for the increasing urban heat island within Philadelphia (Office of Sustainability and ICF International 2015). This analysis provides a method to understand the neighborhoods at risk within the city and areas that should be given priority for GI implementation that can provide a synergistic effect of cooling.

Planning for and managing multiple environmental functions presents a key challenge for planners in complex urban systems (Baró et al. 2017). It is already understood by practitioners and academics that GI practices are not homogenous. Implementing GI that is multifunctional, designed for the complex urban system, and fits within the culture of an area is a delicate balance. Different types of GI provide different benefits: rain gardens facilitate drainage and reduce surface runoff and discharge; green roofs increase the thermal performance of buildings; while biofiltration swales maintain water quality (Jones and Somper 2014). Other studies have analyzed the potential of multiple ecosystem functions at the city scale and have found mismatches between the current supply and demand (Baró et al. 2017), and predict future mismatches as well (Stürck et al. 2015). We have identified a disparity in the multifunctionality of GCCW's GI (Fig. 6). The analysis demonstrated that a large amount of GI lacks in the ability to support local surface temperature regulation, even when it properly provides runoff mitigation services. Conversely, we identified GI areas where runoff was above average and surface temperatures were below average. These areas are mostly located in areas of low-density development. Each of these mismatches were found to be more common in forms of nonvegetative GI. GI practices that do not include vegetation offer fewer opportunities to provide local climate regulation through the provision of cooler microclimates. In the future, Philadelphia should plan to implement more vegetative forms of GI, such as rain gardens and green roofs, that reduce stormwater as well as cool the surrounding area, resulting in enhanced climate change resilience.

As urbanization and climate change continue over time, areas throughout the City will inevitably increase in need for these regulating functions (Baró et al. 2017), highlighting the importance of the multifunctionality that can be gained through single GI installations. Focusing on the systematic factors of physical infrastructure and institutions, this study presents a methodology for assessing GI policies and their ability to enhance climate change resilience. Spatially evaluating the link between policies and physical infrastructure can be key to understanding an area's future resilience to external drivers of change, like climate change (Andersson et al. 2019).

Limitations of this study include the coarse nature of modeling surface temperature and runoff predictions. Availability of more spatially distributed ambient temperatures and empirical measurements of change in temperature with change in landcover would improve the ST Model. Accounting for hydrologic structure and flow would improve the stormwater prediction. In addition, as a case study, the results from this work may be limited because the drivers of landcover change, consequences of climate change, and institutions and policies differ in each city.

\section{CONCLUSION}

The physical infrastructure and institutional framework of the GI program, Green City, Clean Waters, in Philadelphia, PA was analyzed to understand how it might support future climate change resilience. The program serves as a case study to understand how multifunctional GI planning today can enhance climate change resilience in cities in the future through climate regulating ES. Philadelphia's GI program was found to enhance climate change resilience in some areas of the city by decreasing both runoff and surface temperature over time, but more so in some neighborhoods than others depending on the local level of urbanization. The spatial distribution of GI systems must be considered holistically to increase potential benefits across neighborhoods. Furthermore, our work identified that institutional policies and narrowly focused regulatory requirements can hinder the ability to maximize climate change resilience cobenefits. Because PWD's GCCW plan is strictly focused on the goal of reducing stormwater runoff, we identify a missed opportunity to increase cobenefits, particularly in installing vegetated GIs in a systemic manner that can contribute to local climate regulation. Green City, Clean Waters, although envisioned to be a multibenefit plan, is, at its core, a program developed to meet water quality-based regulations. However, climate resilience is a citywide goal and therefore the development and implementation of climate resilience strategies and policies cannot be the responsibility of any single agency or institution. Without policies across various city agencies that promote city greening, integrated with GI systems as a high priority measure to increase Philadelphia's resilience, maximizing the multiple cobenefits of these systems will remain challenging.

Because the city is predicted to keep urbanizing, runoff and surface temperature will continue to increase in many areas. For effective climate change resiliency to be achieved, green infrastructure projects will have to continue after the end of GCCW in 2036. Design and implementation of these projects should consider multiple drivers, including climate change adaptation to increasing rainfall and higher temperatures. More in-depth studies using specific types of GI and surface temperature data at a finer resolution are needed to fully understand potential benefits. Because climate change continues to increase not just the average temperature and amount of precipitation, but also the number of very hot and very rainy days in Philadelphia, more research will be needed to understand how the new climate will affect residents, especially vulnerable populations. Green infrastructure serves as a multibeneficial method to alleviate some of the effects of climate change, as cities around the world strive to be resilient and maintain today's current functions well into the future.

[1] As declared by the USGS (2018): "USGS Landsat Surface Temperature Science Product may report unvalidated results for certain observational conditions."

Responses to this article can be read online at: https://www.ecologyandsociety.org/issues/responses. php/12076 


\section{Acknowledgments:}

Thank you to Dr. Yimin Zhang in the Department of Mathematics and Statistics at Villanova University for her support and generous advice on temperature analysis.

\section{Data Availability:}

Data openly available in a public repository that issues datasets with DOIs. The data that support the findings of this study are openly available in Open Science Frameworks at https:/losf.iolfbca9l, reference number 10.17605/OSF.IO/FBCA9. Datalcode derived from public domain resources: The data that support the findings of this study are available in OpenDataPhilly at https://www. opendataphilly.org/. These data were derived from the following resources available in the public domain: Stormwater Management Practice Polygons: https://www.opendataphilly.org/dataset/greeninfrastructure-constructed-project-polygons City Limits: https:// www.opendataphilly.org/dataset/city-limits Datalcode derived from public domain resources: The data that support the findings of this study are available in the Pennsylvania Spatial Data Access Clearinghouse at https:/lwww.pasda.psu.edu". These data were derived from the following resources available in the public domain: Philadelphia Land Cover Raster 2008: https://www.pasda.psu.edul ucilDataSummary.aspx? dataset $=138$.

\section{LITERATURE CITED}

Andersson, E., J. Langemeyer, S. Borgström, T. McPhearson, D. Haase, J. Kronenberg, D. N. Barton, M. Davis, S. Naumann, L. Röschel, and F. Baró. 2019. Enabling green and blue infrastructure to improve contributions to human well-being and equity in urban systems. BioScience 69(7):566-574. https://doi. org/10.1093/biosci/biz058

Borgström, S. T., T. Elmqvist, P. Angelstam, and C. AlfsenNorodom. 2006. Scale mismatches in management of urban landscapes. Ecology and Society 11(2):16. https://doi.org/10.5751/ es-01819-110216

Baró, F., E. Góez-Baggethun, and D. Haase. 2017. Ecosystem service bundles along the urban-rural gradient: insights for landscape planning and management. Ecosystem Services 24:147-159. https://doi.org/10.1016/j.ecoser.2017.02.021

Brown, A., A. Dayal, and C. Rumbaitis Del Rio. 2012. From practice to theory: emerging lessons from Asia for building urban climate change resilience. Environment and Urbanization 24 (2):531-556. https://doi.org/10.1177/0956247812456490

Bureau of Reclamation. 2014. Downscaled CMIP3 and CMIP5 Climate and Hydrology Projections: Release of Downscaled CMIP5 Climate Projections, Comparison with preceding Information, and Summary of User Needs. U.S. Department of the Interior, Bureau of Reclamation, Technical Services Center, Denver, Colorado, USA.

Cejudo, G. M., and C. L. Michel. 2017. Addressing fragmented government action: coordination, coherence, and integration. Policy Sciences 50(4):745-767. https://doi.org/10.1007/s11077-017-9281-5

Cook, M. J. 2014. Atmospheric compensation for a Landsat land surface temperature product land surface temperature.
Dissertation. Rochester Institute of Technology, Rochester, New York, USA.

Cook, M., J. R. Schott, J. Mandel, and N. Raqueno. 2014. Development of an operational calibration methodology for the Landsat thermal data archive and initial testing of the atmospheric compensation component of a land surface temperature (LST) product from the archive. Remote Sensing 6 (11):11244-11266. https://doi.org/10.3390/rs61111244

Demuzere, M., K. Orru, O. Heidrich, E. Olazabal, D. Geneletti, H. Orru, A. G. Bhave, N. Mittal, E. Feliu, and M. Faehnle. 2014. Mitigating and adapting to climate change: multi-functional and multi-scale assessment of green urban infrastructure. Journal of Environmental Management 146:107-115. https://doi.org/10.1016/ j.jenvman.2014.07.025

ESRI. 2018. ArcGIS. ESRI, Redlands, California, USA.

Gill, S. E., J. F. Handley, A. Ennos, and S. Pauleit. 2007. Adapting cities for climate change: the role of the green infrastructure. Built Environment 33(1):115-133. https://doi.org/10.2148/benv.33.1.115

Grimm, N. B., E. M. Cook, R. L. Hale, and D. M. Iwaniec. 2015. A broader framing of ecosystem services in cities. Chapter 14 in K. C. Seto, W. D. Solecki, and C. A. Griffith, editors. The Routledge Handbook of Urbanization and Global Environmental Change. Routledge, London, UK.

Hamstead, Z. A., P. Kremer, N. Larondelle, T. McPhearson, and D. Haase. 2016. Classification of the heterogeneous structure of urban landscapes (STURLA) as an indicator of landscape function applied to surface temperature in New York City. Ecological Indicators 70:574-585. https://doi.org/10.1016/j. ecolind.2015.10.014

Hrdalo, I., D. Tomić, and P. Pereković. 2015. Implementation of green infrastructure principles in Dubrovnik, Croatia to minimize climate change problems. Urbani Izziv 26:S38-S49. https://doi. org/10.5379/urbani-izziv-en-2015-26-supplement-003

ICF International. 2016. U.S. DOT CMIP Climate Data Processing Tool User's Guide. ICF International, Fairfax, Virginia, USA.

Jones, S., and C. Somper. 2014. The role of green infrastructure in climate change adaptation in London. Geographical Journal 180(2):191-196. https://doi.org/10.1111/geoj.12059

Kabisch, N., J. Stadler, H. Korn, and A. Bonn. 2017. Naturebased solutions for societal goals under climate change in urban areas - synthesis and ways forward. Pages 323-336 in N. Kabisch, H. Korn, J. Stadler, and A. Bonn, editors. Nature-based solutions to climate change adaptation in urban areas. Springer, Cham, Switzerland. https://doi.org/10.1007/978-3-319-56091-5 19

Kremer, P., N. Larondelle, Y. Zhang, E. Pasles, and D. Haase. 2018. Within-class and neighborhood effects on the relationship between composite urban classes and surface temperature. Sustainability 10(3):645. https://doi.org/10.3390/su10030645

Lim, K. J., and B. A. Engel, S. Muthukrishnan, and J. Harbor. 2006. Effects of initial abstraction and urbanization on estimated runoff using CN technology. Journal of the American Water Resources Association 42(3):629-643. https://doi.org/10.1111/ j.1752-1688.2006.tb04481.x 
Ling, L., and Z. Yusop. 2014. A micro focus with macro impact: exploration of initial abstraction coefficient ratio $(\lambda)$ in Soil Conservation Curve Number (CN) methodology. IOP Conference Series: Earth and Environmental Science 18(1):012121. https://doi.org/10.1088/1755-1315/18/1/012121

Liu, Y., V. F. Bralts, and B. A. Engel. 2015. Evaluating the effectiveness of management practices on hydrology and water quality at watershed scale with a rainfall-runoff model. Science of the Total Environment 511:298-308. https://doi.org/10.1016/j. scitotenv.2014.12.077

Maimone, M., S. Malter, J. Rockwell, and V. Raj. 2019. Transforming global climate model precipitation output for use in urban stormwater applications. Journal of Water Resources Planning and Management 145(6):04019021. https://doi. org/10.1061/(ASCE)WR.1943-5452.0001071

Maragno, D., M. Gaglio, M. Robbi, F. Appiotti, E. A. Fano, and E. Gissi. 2018. Fine-scale analysis of urban flooding reduction from green infrastructure: an ecosystem services approach for the management of water flows. Ecological Modelling 386:1-10. https://doi.org/10.1016/j.ecolmodel.2018.08.002

Maurer, E. P., L. Brekke, T. Pruitt, and P. B. Duffy. 2007. Fineresolution climate projections enhance regional climate change impact studies. Eos, Transactions American Geophysical Union 88 (47):504. https://doi.org/10.1029/2007EO470006

Meerow, S., and J. P. Newell. 2017. Spatial planning for multifunctional green infrastructure: growing resilience in Detroit. Landscape and Urban Planning 159:62-75. https://doi. org/10.1016/j.landurbplan.2016.10.005

Meinshausen, M., S. J. Smith, K. Calvin, J. S. Daniel, M. L. T. Kainuma, J.-F. Lamarque, K. Matsumoto, S. A. Montzka, S. C. B. Raper, K. Riahi, A. Thomson, G. J. M. Velders, and D. P. P. van Vuuren. 2011. The RCP greenhouse gas concentrations and their extensions from 1765 to 2300. Climatic Change 109(1):213. https://doi.org/10.1007/s10584-011-0156-Z

Menne, M. J., I. Durre, B. Korzeniewski, S. McNeal, K. Thomas, X. Yin, S. Anthony, R. Ray, R. S. Vose, B. E. Gleason, and T. G. Houston. 2012. Global historical climatology network - daily (GHCN-Daily) Version 3.12. NOAA National Climatic Data Center.

Moss, R., M. Babiker, S. Brinkman, E. Calvo, T. Carter, J. Edmonds, I. Elgizouli, S. Emori, L. Erda, K. Hibbard, R. Jones, M. Kainuma, J. Kelleher, J. F. Lamarque, M. Manning, B. Matthews, J. Meehl, L. Meyer, J. Mitchell, N. Nakicenovic, B. O'Neill, R. Pichs, K. Riahi, S. Rose, P. Runci, R. Stouffer, D. van Vuuren, J. Weyant, T. Wilbanks, J. P. van Ypersele, and M. Zurek. 2008. Towards new scenarios for analysis of emissions, climate change, impacts, and response strategies. Intergovernmental Panel on Climate Change, Geneva, Switzerland.

National Oceanic and Atmospheric Administration (NOAA). 2019. Local climatological data. National Centers for Environmental Information, Washington, D.C., USA.

Office of Sustainability and ICF International. 2015. Growing stronger: toward a climate-ready Philadelphia. Mayor's Office of Sustainability, Philadelphia, Pennsylvania, USA.
Philadelphia Water Department. [date unknown]. Hydrologic soil group. City of Philadelphia, Pennsylvania, USA.

Philadelphia Water Department. 2011. Green city, clean waters: the City of Philadelphia's program for combined sewer overflow control. City of Philadelphia, Pennsylvania, USA.

Philadelphia Water Department. 2016. Green city, clean waters evaluation and adaptation plan. City of Philadelphia, Pennsylvania, USA.

Philadelphia Water Department. 2018a. The Philadelphia stormwater management guidance manual. City of Philadelphia, Pennsylvania, USA.

Philadelphia Water Department. 2018b. Green stormwater infrastructure projects. City of Philadelphia, Pennsylvania, USA.

Schwarz, N., A. Bauer, and D. Haase. 2011. Assessing climate impacts of planning policies - an estimation for the urban region of Leipzig (Germany). Environmental Impact Assessment Review 31(2):97-111. https://doi.org/10.1016/j.eiar.2010.02.002

Shade, C., and P. Kremer. 2019. Predicting land use changes in Philadelphia following green infrastructure policies. Land 8(2):28. https://doi.org/10.3390/land8020028

Stead, D., and E. Meijers. 2009. Spatial planning and policy integration: concepts, facilitators and inhibitors. Planning Theory and Practice 10(3):317-332. https://doi.org/10.1080/14649350903229752

Stürck, J., C. J. E. Schulp, and P. H. Verburg. 2015. Spatiotemporal dynamics of regulating ecosystem services in Europe: the role of past and future land use change. Applied Geography 63:121-135. https://doi.org/10.1016/j.apgeog.2015.06.009

Sussams, L. W., W. R. Sheate, and R. P. Eales. 2015. Green infrastructure as a climate change adaptation policy intervention: muddying the waters or clearing a path to a more secure future? Journal of Environmental Management 147:184-193. https://doi. org/10.1016/j.jenvman.2014.09.003

The Center for Neighborhood Technology. 2007. Green values stormwater calculator methodology. The Center for Neighborhood Technology, Chicago, Illinois, USA.

U.S. Department of Agriculture (USDA). 1986. Urban hydrology for small watersheds. TR-55. USDA, Washington, D.C., USA.

U.S. Geological Survey (USGS). 2018. Landsat level 2 surface temperature science product. USGS, Reston, Virginia, USA.

Valparaiso Engineering Department. [date unknown]. City of Valparaiso Stormwater Management Manual. Valparaiso, Indiana, USA. [online] URL: https://ci.valparaiso.in.us/ DocumentCenter/View/1401/SWMM COMPLETE red?bidId=

Water Environment Research Foundation. 2009. Using rainwater to grow livable communities. Sustainable stormwater best management practices. Water Environment Research Foundation, Alexandria, Virginia, USA. [online] URL: https://www.werf.org/ liveablecommunities/toolbox/model.htm 